\title{
CORRECTION
}

\section{Correction to: A robust self-weighted SELO regression model}

\author{
Meihong $\mathrm{Su}^{2} \cdot$ Yaqing Guo ${ }^{2} \cdot$ Changqian $\mathrm{Men}^{2} \cdot$ Wenjian Wang ${ }^{1}$
}

Published online: 28 February 2020

(c) Springer-Verlag GmbH Germany, part of Springer Nature 2020

\section{Correction to: \\ International Journal of Machine Learning and Cybernetics (2019) 10:3189-3199 \\ https://doi.org/10.1007/s13042-019-01009-1}

In the print published article, the reference 19 was published incorrectly and the correct reference is given below.

Omara TM (2017) Weighted robust lasso and adaptive elastic net method for regularization and variable selection in robust regression with optimal scaling transformations. Am J Math Stat 7(2):71-77.

Publisher's Note Springer Nature remains neutral with regard to jurisdictional claims in published maps and institutional affiliations.

The original article can be found online at https://doi.org/10.1007/ s13042-019-01009-1.

Wenjian Wang

wjwang@sxu.edu.cn

1 Key Laboratory of Computational Intelligence and Chinese Information Processing (Shanxi University), Ministry of Education, Taiyuan 030006, China

2 School of Computer and Information Technology, Shanxi University, Taiyuan 030006, China 